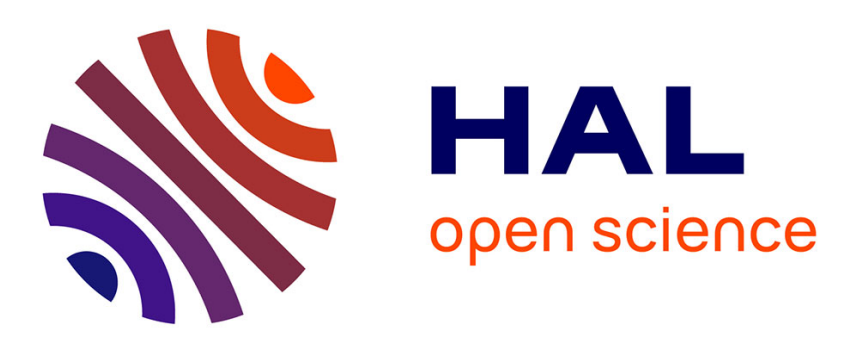

\title{
Theoretical impact of workplace-based primary prevention of lumbar disc surgery in a French region A pilot study
}

Natacha Fouquet, Audrey Petit, Alexis Descatha, Yves Roquelaure

\section{- To cite this version:}

Natacha Fouquet, Audrey Petit, Alexis Descatha, Yves Roquelaure. Theoretical impact of workplacebased primary prevention of lumbar disc surgery in a French region A pilot study. WORK, 2019, 62 (1), pp.13-20. 10.3233/WOR-182837 . hal-02061627

HAL Id: hal-02061627

https://hal-univ-rennes1.archives-ouvertes.fr/hal-02061627

Submitted on 4 Mar 2020

HAL is a multi-disciplinary open access archive for the deposit and dissemination of scientific research documents, whether they are published or not. The documents may come from teaching and research institutions in France or abroad, or from public or private research centers.
L'archive ouverte pluridisciplinaire HAL, est destinée au dépôt et à la diffusion de documents scientifiques de niveau recherche, publiés ou non, émanant des établissements d'enseignement et de recherche français ou étrangers, des laboratoires publics ou privés. 


\title{
Theoretical impact of workplace-based primary prevention of lumbar disc surgery in a French region: a pilot study
}

\author{
N Fouquet ${ }^{1(घ)}$, A Petit ${ }^{2}$, A Descatha ${ }^{3}$, Y Roquelaure ${ }^{2}$ \\ ${ }^{1}$ Santé publique France, the French national public health agency, Direction of Occupational Health, EpiprevTMS team \\ associated to the University of Angers, Angers, France \\ ${ }^{2}$ INSERM, U1085, IRSET, ESTER Team, University of Angers, Angers, France \\ natacha.fouquet@univ-angers.fr \\ ${ }^{3}$ INSERM UMS 011, Population Based Epidemiological Cohorts Unit, University Versailles St-Quentin, Versailles, France \\ natacha.fouqueteuniv-angers.fr
}

\begin{abstract}
Background: Lumbar disc-related disorders are a main cause of work-related osteo-articular morbidity. Lumbar disc surgery (LDS) has been chosen as sentinel event for the epidemiological surveillance of these disorders since LDS can be identified in the medical databases from public and private hospitals. Objective: To assess the theoretical impact of workplace-based primary interventions designed to reduce exposure to personal and/or workrelated risk factors for LDS. Methods: Cases of LDS were assessed using hospital discharge records for persons aged 20-64 in 2007-8 in the French Pays de la Loire region. We estimated the number of work-related cases of LDS (WRLDS) in high-risk industry sectors. Three theoretical scenarios of workplace-based primary prevention have been simulated: a mono-component work-centered intervention reducing the incidence of WR-LDS by $10 \%$, and two multicomponent global interventions reducing the incidence of all cases of LDS by $5 \%$ and $10 \%$ by targeting personal and occupational risk factors. Results: Four high-risk sectors were identified, amounting to 277 [216-352] cases, of which 98 [37-175] were WR-LDS: construction and information \& communication for men; wholesale \& retail trade and accommodation \& food service activities for women. AFE was limited for each industry sector, 30\%, 50\%, 33\% and 55\%, respectively. Conclusions: Prevention scenarios combining actions on personal and occupational risk factors would be the most effective, compared to prevention focused only on occupational risk factors. Implementing actions of promotion of health at work would be necessary in addition of actions on occupational risks.
\end{abstract}

Keywords: Lumbar disc-related disorders, work-related, attributable risk, simulation, preventive efficiency. 


\section{Introduction}

Low back pain (LBP), defined as spinal pain/discomfort below the thoracic-lumbar junction (T12-L1) to the inferior gluteal fold [1], is a major public health issue in many industrialized countries [2] that extends worldwide [3], with high prevalence in the general population.

In developed countries, LBP is among the sixth health problem in terms of costs and among the first three sources of disabling pain [4], especially in working age groups [5]. Indeed, LBP is responsible for pain, disability and handicap. It causes considerable human and social costs in terms of pain and discomfort in the workplace and everyday life $[6,7]$ and of health-related quality of life [8]. It is a source of sometimes severe functional sequelae, impairment of working capacity and career disruption for people and considerable costs for the society [9]. It generates substantial direct costs associated with seeking medical and paramedical care and diagnostic procedures and more particularly indirect costs (compensation, job loss, 'absenteism', 'presenteism', etc.) which are 5-6 times higher [10-13]. In addition to the intensity of pain, the severity of LBP is mainly due to the disability it causes $[14,15]$.

LBP is a complex symptom, and the type of contributors to both the pain and associated disability are multiple: lifestyle, psychological, social, biophysical, occupational...[5]

To prevent LBP and associated disability, guidelines recommend mainly self-management, physical and psychological therapies. According to Foster and al. [16], promising solutions to prevent LBP include focused "implementation of best practice, the redesign of clinical pathways, integrated health and occupational care, changes to payment systems and legislation, and public health and prevention strategies".

The multifactorial origin of LBP makes it difficult to distinguish the relative contribution of personal and workrelated factors at the individual level. However, at the population level a substantial number of LBP are mainly related to workers' personal characteristics and medical conditions. Cases that occur regardless of work exposures will be called 'personal-related' (PR) LBP in the remaining part of the text. Other cases occurring in excess in workers employed in jobs at high risk for LBP can be considered as mainly work-related or 'attributable to work'. The proportion of 'work-related' (WR) LBP can be estimated by the work-related attributable fraction of risk (AFE). 
The reduction of LBP and associated disability in the workforce is a priority for policy makers due to the human, social and economic costs. Work-centered ergonomic interventions (WI) include ergonomic and organizational adaptation of the workplace. Some multifaceted global interventions (GI) add to the WI component various components of personal interventions (PI), such as worksite behavioral programs (e.g., social health promotion, exercise), education programs (e.g., education and training on risk-reducing working techniques) and diet programs to manage overweight $[16,17]$.

Multi-component global interventions (GI) including both personal behavioral interventions (PI components) and collective technical, ergonomic and organizational interventions (WI components) are considered the most promising preventive approach for LBP among workers $[16,18]$. However, it's accepted in the evidence-based literature that primary prevention of LBP is inadequate; whereas secondary prevention programs on associated disability are more appropriate [16].

From a theoretical point of view, WIs focusing on work-related risk factors are expected to reduce mainly WRLBP; their impact will depend on the proportion of cases attributable to work. Higher values can be expected for interventions focusing on some jobs at particularly high risks (high AFEs). Primary multi-component global interventions (GI) are expected to be the most efficient in targeting both PR-LBP and WR-LBP, regardless of the AFE value $[19,20]$. However, we still lack information on the joined effects of reducing occupational and nonoccupational risk factors.

The French national public health agency, Santé publique France, implemented a multilevel epidemiological surveillance system for work-related musculoskeletal disorders (MSDs) in the Pays de la Loire region (5\% of French working population) [21] to identify occupations and sectors at high risk. The diseases analyzed in this program comprised those clearly identified as having a significant occupational component and risk factors whose effects are sufficiently established, and identified determinants and misunderstood phenomena [22, 23]. Although it has been shown that beliefs, expectations and preferences of patients and health-care practitioners may influence health care-seeking behavior for LBP, $[24,25]$ lumbar disc surgery (LDS), which can be identified in the medical databases from public and private hospitals [22], was chosen as the sentinel event for disc-related sciatica (DRS) and generally for LBP. A study was conducted in 2007-2008 in the Pays de la Loire region [22] that assessed the proportion of LDS attributable to work according to industry sectors. 
Based on a similar approach in a recent article about carpal tunnel syndrome [26], the aim of this study was to assess the theoretical impact of workplace-based primary interventions designed to reduce exposure to personal and/or work-related risk factors for LDS.

\section{Methods}

Institutional review board approval: The Pays de la Loire study received the approval of the French National Committee for Data Protection (CNIL: Commission Nationale Informatique et Liberté).

Population: The population included in this surveillance program was made up of residents of the Pays de la Loire region (Loire Valley area, west central France) in the 20-64 age group (999,396 women and 995,883 men), whether they were professionally active or not, in 2009 . According to the 2009 census data, the region has $5.7 \%$ of the French population, with a diversified socioeconomic structure [27].

Outcomes: The hospital discharge database of the French National Medical Information Systems Program (PMSI) was analyzed to include all patients aged 20 to 64 years residing in the region and having undergone LDS (list of the codes for surgical acts selected from PMSI database is detailed in a previous article [22]) in 2009.

Occupational history: Due to a lack of information on employment status in the PMSI database, we used data collected by a pilot study conducted among 3,150 persons having undergone LDS in in the participating surgical centers (10 of the 14 regional centers for spinal surgery, representing 93\% of LDS in the region in 2007) [22]. Each eligible patient was informed of the study by the surgeon and a consent form and a self-administered questionnaire were sent to collect medical and surgical history and employment history (industry, occupation and description of tasks throughout employment). For each occupation, industry sector was coded using the 2-digit codes of the French version of the statistical classification of economic activities in the European Community. The analysis was performed on the longest occupation of each entire working life before LDS, only for those employed at the time of surgery.

Scenarios of prevention: As in a previous study of carpal tunnel syndrome [26], in absence of precise data in the literature, we arbitrarily hypothesized that interventions could reduce the incidence of LDS by $10 \%$ in high-risk jobs, and simulated three scenarios of workplace-based primary prevention, differing by their main target: 
- 10\% WI: mono-component work-centered intervention targeting only work-related risk factors for LDS (e.g., ergonomic intervention: workstation redesign, establishment of an ergonomics task force, job rotation, ergonomics training, etc.) expected to reduce WR-LDS by $10 \%$;

- 5\%-GI and 10\% GIs: multi-component global interventions targeting both personal and work-related risk factors for LDS and expected to reduce both PR-LDS and WR-LDS by $5 \%$ or $10 \%$, respectively.

Statistical analysis: Incidence rates of LDS in the whole population were computed separately for each gender. Using the information from the 2007-2008 pilot study, three indicators were computed: the age-adjusted standardized incidence ratios of LDS calculated for each sector with all other sectors as reference $\left(S_{\text {sector-LDS }}\right)$, the age-adjusted relative risks of LDS according to sector computed using the Mantel-Haenszel method (aRR $R_{\text {sector- }}$ $L D S$ ), with the whole sample of subjects included in the study as reference, and the age-adjusted attributable fraction of risk in exposed individuals (AFE) which estimates the proportion of LDS attributable to work in the sectors at high risk of $\operatorname{LDS}[22,28]: A F E_{\text {sector-LDS }}=\left(a R R_{\text {sector-LDS }}-1\right) / a R R_{\text {sector-LDS }}$.

These indicators were computed for each sector when (i) more than 10 men or women were employed and (ii) $a R R_{\text {sector-LDS }}$ was significantly higher than 1 . Sectors at high risk of LDS in comparison with the whole population were thus detected and called "high-risk sectors". Then, specific incidence rates $\left(I_{\text {sector-LDS }}\right)$ were computed according to high-risk sectors. The total number of LDS $\left(N_{\text {sector-LDS }}\right)$ in the sector considered was computed by multiplying the number of workers employed in this sector $\left(N_{e-s e c t o r}\right)$ by the incidence rate in this sector $\left(I_{\text {sector-LDSS }}\right)$. The number of WR-LDS ( $\left.N_{\text {sector-WR-LDS }}\right)$ was calculated by multiplying the total number of LDS $\left(N_{\text {sector-LDS }}\right)$ by the AFE in the sector considered $\left(A F E_{\text {sector-LDS }}\right)[28]$

The preventive efficiency (PE) was estimated as the ratios of LDS hypothetically avoided / total number of LDS (\%) in the sector considered. A 95\% confidence interval was computed only for $S I R_{\text {sector-LDS }}$ and for $a R R_{\text {sector-LDS. }}$ For other indicators, a range was calculated using the lower and upper limits of the considered indicator in the calculation formula. 


\section{Results}

Four industry sectors were at high risk of LDS in the region, amounting to 277 [216-352] LDS cases, of which 98 [37-175] were WR-LDS (Table 1): construction and information \& communication for men; wholesale \& retail trade and accommodation \& food service activities for women. AFE was limited for each industry sector, varying between $30 \%$ for men construction and $55 \%$ for women of accommodation \& food service activities. 
As shown in Table 2, the number of avoidable LDS varied between the different preventive scenarios and sectors. The 10\%-WI, 5\%-GI and 10\%-GI scenarios hypothetically prevented 10 [4-18], 13 [11-17] and 28 [22-36] LDS cases among sectors at risk, respectively. For each sector at risk, the hypothetical preventive efficiency was lower for the $10 \%$-WI scenario compared to the $10 \%$-GI and even the $5 \%$-GI scenarios. Thus, for accommodation \& food service activities for women (the highest AFE) the preventive efficiency was 5.9\% [2.0-13.0] for the $10 \%$ WI scenario, $8.8 \%$ [4.1-21.7] for the $10 \%$-GI scenario and 5.9\% [2.0-8.7] for the 5\%-GI scenario. For construction for men (the lowest AFE) the preventive efficiency was 3.0\% [1.2-6.4] for the 10\%-WI scenario, 9.7\% [6.8-14.5] for the $10 \%$-GI scenario and $5.2 \%[3.7-7.3]$ for the $5 \%$-GI scenario.

\section{Discussion}

Among the four sectors at high risk, AFEs were limited, varying between $30 \%$ for men in construction and $55 \%$ for women in accommodation \& food service activities. This study found that a limited proportion of LDS in a French general working-age population were work-related, and that work-related LDS were concentrated in several high-risk industries.

Surveillance data used for the computation of potentially preventable LDS included data from one of the largest and most complete surveillance programs for LDS, covering an entire region of France [22, 30]. The French PMSI database registering only LDS underestimated cases potentially preventable since disc-related sciatica (DRS) requiring only medical treatment and more generally LBP were not counted. The proportion of DRS requiring surgery is unknown in France. Nevertheless, the rates of disc surgery computed in this region were close to those in France (data not shown), suggesting that no specific regional features of healthcare use or medical practice could explain our results. Given that the PMSI database lacked information relating to occupation and no more recent data were available, we used information on employment of patients undergoing LDS collected in 2007-2008 from all region's hand surgery centers to estimate AFEs of LDS [22]. No exhaustive job exposure data of the working population was available in the Pays de la Loire region, except the job titles collected by the 2009 Census, almost contemporary to our study data. According to the French census data, the distribution of the active population by occupational groups and industry sectors is comparable between 2010 and 2015 [31]. This suggests that, despite the seniority of the used data (2007-8) which is a limitation of this study, the results are relevant.

Certain very high-risk jobs involving few workers may not have been identified in the present study due to the lack of statistical power, and this might have led to underestimating the impact of work-centered prevention. The 
computation of the preventable cases of LDS supposed several hypotheses [28], namely (i) causal relationships between the occurrence of LDS and work exposure and (ii) substantial impact of interventions reducing exposure to risk factors at the workplace [28].

While there are many treatment options to chronic LBP, none are universally endorsed [32]. For a few years, the literature shows that the role of surgery is limited and recommendations in clinical guidelines vary [16]. The idea that chronic LBP is a condition best understood with reference to an interaction of physical, psychological and social influences, the 'biopsychosocial model', has received increasing acceptance.

A biopsychosocial framework, including psychological, social and occupational (organizational, biomechanical...) components, combined to psychological programs for patient with chronic symptoms, is recommended to guide management $[32,33]$. A recent paper underlines the necessity to integrate health and occupational interventions to improve function and return to work rates and to reduce the economic and societal burden of work disability pensions due to LBP [16].

We did not evaluate the hypothetical preventive efficiency of interventions that focus only on personal risk factors, expecting that changes in "personal risk factors" would be an essential component of multifaceted workplace interventions (10\%-GI scenarios)[26]. Combining interventions on personal and work-related factors was assumed to have a higher impact than interventions targeting only on personal or work-related factors [16]. To the best of our knowledge, we still lack data on the impact of multiple global interventions to estimate their joint effects. We have therefore adopted a simplistic additive model. We focused prevention only at the workplace level, although interventions to prevent LDS at the population level might be worth investigating. Indeed, mass-media campaigns about back pain have namely proved to have some success in four countries [16].

This study suggests that prevention efforts to reduce exposure to work-related risk factors should focus on highrisk jobs. Simulated workplace-based mono-component work-centered interventions and multi-component global interventions showed that preventive efficiency varied depending on the intervention design, the number of workers in different jobs and the proportion of work-related LDS. Given that personal risk factors such as obesity or high leisure time stressors are also risk factors for LDS [34], reducing rates of LDS in the general working-age population will also require strategies to reduce personal risk factors, particularly in jobs with low levels of workrelated risk for LDS [20]. 


\section{Conclusion}

Prevention scenarios combining actions on personal and occupational risk factors would be more effective than prevention scenarios focused only on occupational risk factors, even with higher incidence reduction targets. Thus, to reduce the incidence of LDS, implementing actions of promotion of health at work would be necessary in addition of actions on occupational risks.

\section{References}

[1] Ryan CG, Lauchlan D, Rooney L, et al. Returning to work after long term sickness absence due to low back pain - the struggle within: a qualitative study of the patient's experience. Work 2014; 49: 433-44.

[2] Balagué F, Mannion AF, Pellisé F, et al. Non-specific low back pain. Lancet 2012; 379: 482-91.

[3] Louw QA, Morris LD, Grimmer-Somers K. The prevalence of low back pain in Africa: a systematic review. BMC Musculoskelet Disord 2007; 8: 105.

[4] Lamb SE, Hansen Z, Lall R, et al. Group cognitive behavioural treatment for low-back pain in primary care: a randomised controlled trial and cost-effectiveness analysis. Lancet 2010; 375: 916-23.

[5] Hartvigsen J, Hancock MJ, Kongsted A, et al. What low back pain is and why we need to pay attention. Lancet Lond Engl 2018; 391: 2356-67.

[6] Punnett L, Prüss-Utün A, Nelson DI, et al. Estimating the global burden of low back pain attributable to combined occupational exposures. Am J Ind Med 2005; 48: 459-69.

[7] Burton AK, Balagué F, Cardon G, et al. Chapter 2. European guidelines for prevention in low back pain : November 2004. Eur Spine J Off Publ Eur Spine Soc Eur Spinal Deform Soc Eur Sect Cerv Spine Res Soc 2006; 15 Suppl 2: S136-68.

[8] Yamada K, Matsudaira K, Takeshita K, et al. Prevalence of low back pain as the primary pain site and factors associated with low health-related quality of life in a large Japanese population: a pain-associated cross-sectional epidemiological survey. Mod Rheumatol 2014; 24: 343-8.

[9] Dagenais S, Caro J, Haldeman S. A systematic review of low back pain cost of illness studies in the United States and internationally. Spine J Off J North Am Spine Soc 2008; 8: 8-20.

[10] Becker A, Held H, Redaelli M, et al. Low back pain in primary care: costs of care and prediction of future health care utilization. Spine 2010; 35: 1714-20.

[11] Ritzwoller DP, Crounse L, Shetterly S, et al. The association of comorbidities, utilization and costs for patients identified with low back pain. BMC Musculoskelet Disord 2006; 7: 72. 
[12] Walker BF, Muller R, Grant WD. Low back pain in Australian adults: the economic burden. Asia-Pac J Public Health Asia-Pac Acad Consort Public Health 2003; 15: 79-87.

[13] Ravenek MJ, Hughes ID, Ivanovich N, et al. A systematic review of multidisciplinary outcomes in the management of chronic low back pain. Work 2010; 35: 349-67.

[14] Loisel P, Durand P, Abenhaim L, et al. Management of occupational back pain: the Sherbrooke model. Results of a pilot and feasibility study. Occup Environ Med 1994; 51: 597-602.

[15] Loisel P, Lemaire J, Poitras S, et al. Cost-benefit and cost-effectiveness analysis of a disability prevention model for back pain management: a six year follow up study. Occup Environ Med 2002; 59: 807-15.

[16] Foster NE, Anema JR, Cherkin D, et al. Prevention and treatment of low back pain: evidence, challenges, and promising directions. Lancet Lond Engl 2018; 391: 2368-83.

[17] Société française de médecine du travail. Recommandations de Bonne Pratique - Surveillance médico-professionnelle du risque lombaire pour les travailleurs exposés à des manipulations de charges - Argumentaire scientifique. Recommandations de Bonne Pratique, Paris: Société française de médecine du travail, 2013.

[18] Petit A, Mairiaux P, Desarmenien A, et al. French good practice guidelines for management of the risk of low back pain among workers exposed to manual material handling: Hierarchical strategy of risk assessment of work situations. Work 2016; 53: 845-850.

[19] Punnett L, Cherniack M, Henning R, et al. A conceptual framework for integrating workplace health promotion and occupational ergonomics programs. Public Health Rep Wash DC 1974 2009; 124 Suppl 1: 16-25.

[20] Sorensen G, McLellan DL, Sabbath EL, et al. Integrating worksite health protection and health promotion: A conceptual model for intervention and research. Prev Med 2016; 91: 188-196.

[21] Roquelaure Y, Fouquet N, Ha C, et al. Epidemiological surveillance of lumbar disc surgery in the general population: a pilot study in a French region. Jt Bone Spine Rev Rhum 2011; 78: 298302 .

[22] Fouquet N, Descatha A, Ha C, et al. An epidemiological surveillance network of lumbar disc surgery to help prevention of and compensation for low back pain. Eur J Public Health 2016; 26: $543-8$.

[23] Rutstein DD, Mullan RJ, Frazier TM, et al. Sentinel Health Events (occupational): a basis for physician recognition and public health surveillance. Am J Public Health 1983; 73: 1054-62.

[24] Mannion AF, Wieser S, Elfering A. Association Between Beliefs and Care-Seeking Behavior for Low Back Pain: Spine 2013; 38: 1016-25.

[25] Main CJ, Foster N, Buchbinder R. How important are back pain beliefs and expectations for satisfactory recovery from back pain? Best Pract Res Clin Rheumatol 2010; 24: 205-17. 
[26] Roquelaure Y, Fouquet N, Chazelle E, et al. Theoretical impact of simulated workplace-based primary prevention of carpal tunnel syndrome in a French region. BMC Public Health 2018; 18: 426.

[27] INSEE. Population active, emploi et chômage en 2009 - Région des Pays de la Loire (52), https://www.insee.fr/fr/statistiques/2044042?geo=REG-52 (accessed 9 March 2018).

[28] Rockhill B, Newman B, Weinberg C. Use and misuse of population attributable fractions. Am J Public Health 1998; 88: 15-9.

[29] Ha C, Roquelaure Y, Leclerc A, et al. The French Musculoskeletal Disorders Surveillance Program: Pays de la Loire network. Occup Environ Med 2009; 66: 471-479.

[30] Fouquet N, Bodin J, Chazelle E, et al. Use of Multiple Data Sources for Surveillance of WorkRelated Chronic Low-Back Pain and Disc-Related Sciatica in a French Region. Ann Work Expo Health 2018; 62: 530-46.

[31] Insee. Dossier complet - Région des Pays de la Loire (52) | Insee, https://www.insee.fr/fr/statistiques/2011101?geo=REG-52\#graphique-EMP_G3 (accessed 7 November 2018).

[32] Kamper SJ, Apeldoorn AT, Chiarotto A, et al. Multidisciplinary biopsychosocial rehabilitation for chronic low back pain. Cochrane Database Syst Rev 2014; CD000963.

[33] Ravenek MJ, Bryson-Campbell MM, Shaw L, et al. Perspectives on prevention, assessment, and rehabilitation of low back pain in WORK. Work 2010; 35: 269-82.

[34] Mierswa T, Kellmann M. Differences in low back pain occurrence over a 6-month period between four recovery-stress groups. Work 2017; 58: 193-202. 
Table 1. Standardized incident ratios (SIR) and incidence of lumbar disc surgery (LDS), attributable risk fractions among the exposed (AFE) and estimated number of cases of LDS in the high-risk sectors in men or women

\begin{tabular}{|c|c|c|c|c|c|c|c|c|c|c|c|c|c|}
\hline & $\mathrm{N}_{\text {Workers }} \#$ & $\begin{array}{r}\% \\
\text { Workers }^{\mathrm{a}} \\
\end{array}$ & $\begin{array}{c}\text { SIR }_{\text {se }} \\
\text { ctor }\end{array}$ & $95 \%$ & $\mathrm{CI}^{\mathrm{c}}$ & $\mathrm{ILDS}^{\mathrm{d}}$ & Range $^{e}$ & $\mathrm{AFE}^{\mathrm{f}}$ & Range $^{g}$ & $N_{\text {sector-LDS }} \mathrm{h}$ & Range $^{\mathrm{i}}$ & $\begin{array}{l}N_{W R} \\
\text {-LDS } \\
\end{array}$ & Range $^{\mathrm{k}}$ \\
\hline \multicolumn{14}{|c|}{ Construction } \\
\hline Men* & 95,372 & 12.5 & 1.3 & 1.0 & 1.5 & 1.4 & $1.1 \quad 1.7$ & 30.3 & $14.6 \quad 43.1$ & 134 & 110161 & 41 & $16 \quad 69$ \\
\hline Women & 12,595 & 1.8 & 0.6 & 0.2 & 1.3 & 0.4 & $0.1 \quad 1.0$ & & - & & - & & - \\
\hline Total & 107,966 & 7.4 & & & & & & & & & & & \\
\hline \multicolumn{14}{|c|}{ Wholesale \& retail trade } \\
\hline Men & 98,417 & 12.9 & 0.7 & 0.6 & 0.9 & 0.8 & $0.6 \quad 1.0$ & & - & & - & & - \\
\hline Women* & 88,213 & 12.8 & 1.4 & 1.1 & 1.7 & 1.1 & $\begin{array}{ll}0.9 & 1.3\end{array}$ & 32.7 & $15.5 \quad 46.4$ & 95 & $76 \quad 117$ & 31 & 1254 \\
\hline Total & 186,630 & 12.9 & & & & & & & & & & & \\
\hline \multicolumn{14}{|c|}{ Accommodation \& food service activities } \\
\hline Men & 19,969 & 2.6 & 1.0 & 0.5 & 1.6 & 1.1 & $0.6 \quad 1.7$ & & & & & & \\
\hline Women* & 23,305 & 3.4 & 1.9 & 1.3 & 2.7 & 1.5 & $1.0 \quad 2.1$ & 54.9 & $35.1 \quad 68.6$ & 34 & 2349 & 19 & $8 \quad 34$ \\
\hline Total & 43,274 & 3.0 & & & & & & & - & & - & & - \\
\hline \multicolumn{14}{|c|}{ Information \& communication } \\
\hline Men* & 19,358 & 2.5 & 0.7 & 0.3 & 1.2 & 0.7 & $0.4 \quad 1.3$ & 49.6 & 10.571 .6 & 14 & $7 \quad 25$ & 7 & 118 \\
\hline Women & 9,390 & 1.4 & 0.9 & 0.3 & 2.0 & 0.7 & $0.3 \quad 1.5$ & & - & & - & & - \\
\hline Total & 28,748 & 2.0 & & & & & & & & & & & \\
\hline \multicolumn{14}{|c|}{ All high-risk sectors } \\
\hline Men & 114,730 & 15.1 & & & & & & & & 148 & $117 \quad 186$ & 48 & \\
\hline Women & 111,518 & 16.1 & & & & & & & & 129 & $99 \quad 166$ & 50 & $20 \quad 88$ \\
\hline Total & 226,248 & 15.6 & & & & & & & & 277 & $216 \quad 352$ & 98 & $37 \quad 175$ \\
\hline \multicolumn{14}{|c|}{ Active population } \\
\hline Men & 760,849 & 100 & - & & & 1.1 & & & & 827 & & - & \\
\hline Women & 691,273 & 100 & - & & & 0.8 & & & & 614 & & - & \\
\hline Total & $1,452,122$ & 100 & - & & & 0.9 & & & & 1441 & & - & \\
\hline
\end{tabular}

* sectors at high risk of LDS; \# 2009 INSEE Census data; a. \% of the active regional population; b. Standardized incidence ratios of LDS (SIR sector-LDS); c. 95\% confidence interval (CI); d. Incidence of LDS per 1000 persons-years (ILDS); e. Range computed using the lower and upper limits of the $95 \%$ CI of SIR LDS (AFEsector-LDS(\%)); g. Range calculated using the lower and upper limits of the 95\% CI of aRR sector-LDs (data not shown); h. Total number of LDS (N considered; i. Range computed using the number of workers of each sector and gender (N) and the lower and upper limits of the range of Isector-LDs; j. Number of WR-LDS cases

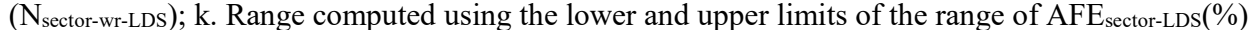


Table 2. Estimated number of preventable cases of lumbar disc surgery (LDS) and preventive efficiency according the 10-WI, 5\%-GI and 10\%-GI preventive intervention scenarios in the high-risk sectors in men or women

\begin{tabular}{|c|c|c|c|c|c|c|c|c|c|c|c|c|c|}
\hline & \multicolumn{7}{|c|}{ Preventable LDS according to preventive scenarios ${ }^{\mathrm{a}}$} & \multicolumn{6}{|c|}{ Preventive efficiency ${ }^{\mathrm{b}}(\%)$} \\
\hline & \multicolumn{2}{|c|}{$10 \%-W I$} & \multicolumn{2}{|c|}{$5 \%-\mathrm{GI}$} & \multicolumn{3}{|c|}{$10 \% \mathrm{GI}$} & \multicolumn{2}{|c|}{$10 \%$-WI } & \multicolumn{2}{|c|}{$5 \%$-GI } & \multicolumn{2}{|c|}{$10 \%-G I$} \\
\hline & $\mathrm{N}$ & Range $^{c}$ & $\mathrm{~N}$ & Range $^{\mathrm{d}}$ & $\mathrm{N}$ & & Range $^{\mathrm{d}}$ & Mean & Range $^{e}$ & Mean & Range $^{\mathrm{f}}$ & Mean & Range $^{f}$ \\
\hline \multicolumn{14}{|c|}{ Construction } \\
\hline Men* & 4 & 27 & 7 & 68 & 13 & 11 & 16 & 3.0 & $1.2 \quad 6.4$ & 5.2 & $3.7 \quad 7.3$ & 9.7 & $6.8 \quad 14.5$ \\
\hline Women & & - & & - & & - & & & - & & - & & - \\
\hline \multicolumn{14}{|l|}{ Total } \\
\hline \multicolumn{14}{|c|}{ Wholesale \& retail trade } \\
\hline Men & & - & & - & & - & & & - & & - & & - \\
\hline Women* & 3 & 15 & 5 & 46 & 10 & 8 & 12 & 3.2 & $0.9 \quad 6.6$ & 5.3 & 3.47 .9 & 10.5 & $6.8 \quad 15.8$ \\
\hline Total & & & & & & & & & & & & & \\
\hline \multicolumn{14}{|c|}{ Accommodation \& food service activities } \\
\hline Men & & - & & - & & - & & & - & & - & & - \\
\hline Women* & 2 & 13 & 2 & 12 & 3 & 2 & 5 & 5.9 & $2.0 \quad 13.0$ & 5.9 & $2.0 \quad 8.7$ & 8.8 & 4.121 .7 \\
\hline \multicolumn{14}{|l|}{ Total } \\
\hline \multicolumn{14}{|c|}{ Information \& communication } \\
\hline Men* & 1 & 02 & 1 & $0 \quad 1$ & 1 & 1 & 3 & 7.1 & $0.0 \quad 28.6$ & 7.1 & $0.0 \quad 14.3$ & 7.1 & $4.0 \quad 42.9$ \\
\hline Women & & - & & - & & - & & & - & & - & & - \\
\hline Total & & & & & & & & & & & & & \\
\hline \multicolumn{14}{|c|}{ All high-risk sectors } \\
\hline Men & 5 & 29 & 7 & 69 & 15 & 12 & 19 & 3.4 & $1.1 \quad 7.7$ & 4.7 & $\begin{array}{ll}3.2 & 7.7\end{array}$ & 10.1 & $6.5 \quad 16.2$ \\
\hline Women & 5 & 29 & 6 & 58 & 13 & 10 & 17 & 3.9 & $\begin{array}{ll}1.2 & 9.1\end{array}$ & 4.7 & $3.0 \quad 8.1$ & 10.1 & $6.0 \quad 17.2$ \\
\hline Total & 10 & $4 \quad 18$ & 13 & $11 \quad 17$ & 28 & 22 & 36 & 3.6 & 1.18 .3 & 4.7 & 3.17 .9 & 10.1 & $6.3 \quad 16.7$ \\
\hline
\end{tabular}

* sectors at high risk of LDS; \# 2009 INSEE Census data; a. $10 \% \mathrm{WI}$ : mono-component work-centered interventions targeting only work-related risk factors and expected to reduce WR-LDS cases by $10 \% ; 5 \%$-GI and $10 \% \mathrm{GI}$ : multi-component global interventions targeting personal and work-related risk factors for LDS and expected to reduce both PR-LDS and WR-LDS by $5 \%$ or $10 \%$, respectively; b. ratios of LDS hypothetically avoided / total number of LDS (\%) in the sector considered, computed only if one of the inferior range is superior than 0 ; $\mathrm{c}$. Range calculated using the lower and upper limits of the range of the number of WR-LDS cases $\left(\mathrm{N}_{\text {sector-wr-LDS }}\right)$; $\mathrm{d}$. Range computed using the lower and upper limits of the range of $\mathrm{N}_{\text {sector-LDs; }}$ e. Lower limit of range of PE $=$ lower limit of range of WR-LDS hypothetically avoided / Upper limit of range of total number of WR-LDS and Upper limit of range of PE = Upper limit of range of WR-LDS hypothetically avoided / Lower limit of range of total number of WR-LDS; f. Lower limit of range of PE = lower limit of range of LDS hypothetically avoided / Upper limit of range of total number of LDS and Upper limit of range of PE = Upper limit of range of LDS hypothetically avoided / Lower limit of range of total number of LDS 
